OPEN ACCESS

Edited by:

Björn Tampe,

University Medical Center

Göttingen, Germany

Reviewed by:

Shoji Saito

Nagoya University, Japan

Maja Zivotic,

University of Belgrade, Serbia

*Correspondence:

Yoshiyuki Morishita

ymori@jichi.ac.jp

Specialty section:

This article was submitted to

Nephrology,

a section of the journa

Frontiers in Medicine

Received: 31 August 2021 Accepted: 15 October 2021

Published: 05 November 2021

Citation:

Kaneko S, Yanai K, Kitano T, Miyazawa H, Hirai K, Ookawara S and Morishita Y (2021) Change in Anemia

by Carnitine Supplementation in Patients Undergoing Peritoneal

Dialysis: A Retrospective

Observational Study.

Front. Med. 8:767945

doi: 10.3389/fmed.2021.767945

\section{Change in Anemia by Carnitine Supplementation in Patients Undergoing Peritoneal Dialysis: A Retrospective Observational Study}

\author{
Shohei Kaneko, Katsunori Yanai, Taisuke Kitano, Haruhisa Miyazawa, Keiji Hirai, \\ Susumu Ookawara and Yoshiyuki Morishita* \\ Division of Nephrology, First Department of Integrated Medicine, Saitama Medical Center, Jichi Medical University, Saitama, \\ Japan
}

Background: Carnitine supplementation improves various dialysis-related symptoms including erythropoietin-resistant anemia in patients who are undergoing hemodialysis. However, the utility of carnitine supplementation in patients who are undergoing peritoneal dialysis (PD) is not fully understood.

Methods: Thirteen patients undergoing PD [mean age: $54.2 \pm 14.8$ years, males: 9/13 (69\%)] administered oral carnitine supplementation (mean dose: $9.1 \pm 3.3 \mathrm{mg} / \mathrm{kg} /$ day) for 4-6 months were retrospectively investigated. Changes in serum carnitine levels and other clinical variables including the erythropoietin resistance index (ERI) were analyzed after carnitine supplementation.

Results: Carnitine supplementation increased serum total carnitine (48.5 \pm 10.2 vs. $130.1 \pm 37.2 \mu \mathrm{mol} / \mathrm{L}, P<0.01)$, free carnitine $(31.1 \pm 8.3 \mathrm{vs} .83 .1 \pm 24.6 \mu \mathrm{mol} / \mathrm{L}$, $P<0.01)$, and acyl carnitine (17.4 \pm 2.8 vs. $46.9 \pm 13.8, P<0.01)$ levels. The acyl carnitine/free carnitine ratio was not affected $(0.6 \pm 0.1$ vs. $0.6 \pm 0.1, P=0.75)$. Although the mean ERI was not affected by carnitine supplementation [13.7 \pm 4.7 vs. $11.6 \pm 3.4 \mathrm{IU} / \mathrm{kg} /(\mathrm{g} / \mathrm{dL}) /$ week, $P=0.28]$, the $\mathrm{ERI}$ change rate was significantly decreased (1.00 \pm 0.00 vs. $0.87 \pm 0.11, P<0.01)$.

Conclusion: Carnitine supplementation may improve erythropoietin resistance in patients who are undergoing PD.

\footnotetext{
Keywords: carnitine deficiency, carnitine supplementation, peritoneal dialysis, erythropoietin resistance index, erythropoietin-resistant anemia
}

\section{INTRODUCTION}

Carnitine is a water-soluble amino acid derivative with a molecular weight of $161 \mathrm{Da}$, and it has an important role in fatty acid metabolism in skeletal muscle (1-3). Seventy-five percent of the human body requirement for carnitine is obtained from the diet such as red meat, while the remaining $25 \%$ is biosynthesized in the kidneys and liver $(4,5)$. Carnitine exists in different forms in serum including free carnitine and acyl carnitine $(6,7)$. Total carnitine is the sum of free carnitine and acyl carnitine $(6,7)$. Free carnitine is converted to acyl carnitine by binding acyl residues, and it can transfer acyl residues into mitochondria for use as an energy source $(1,2)$. However, excess 
and harmful acyl residues are also discharged as acyl carnitines $(1,2)$. Therefore, to maintain homeostasis of energy metabolism, the different forms of carnitine must be properly balanced.

Low serum free carnitine and/or high acyl carnitine/free carnitine ratio generally result in diagnosis of carnitine deficiency (8). In the healthy population, the frequency of carnitine deficiency is very low because carnitine is supplied satisfactorily through diet and renal and hepatic biosynthesis $(4,5)$. However, carnitine deficiency is frequently observed in patients undergoing hemodialysis $(4,9,10)$. Possible mechanisms for the deficiency include dietary restrictions attributed to renal failure, decreased biosynthesis, and exposure to dialysate $(11,12)$. Previous studies have reported a loss of more than $60 \%$ of free carnitine in one hemodialysis session (13). Additionally, a Japanese research group recently reported that hemodiafiltration contributed more to carnitine loss than hemodialysis (hemodialysis $64 \%$ $\pm 4 \%$ vs. hemodiafiltration $75 \% \pm 7 \%$ ) (10). Typically, carnitine deficiency is associated with various symptoms such as erythropoietin-resistant anemia, muscle weakness, cardiac dysfunction, and intradialytic hypotension (14). Additionally, recent studies have suggested an association between carnitine deficiency and conditions such as glucose metabolism disorders and liver dysfunction (15-18). National Kidney Foundation guidelines recommend carnitine supplementation for patients with carnitine deficiency undergoing hemodialysis (14).

However, at this time, only a few reports have investigated carnitine deficiency in patients undergoing peritoneal dialysis (PD) (19-21). Clinicians should note that the National Kidney Foundation guidelines are not sufficiently supported by reports of carnitine deficiency in patients undergoing PD (14). Under these circumstances, we previously reported a high prevalence of carnitine deficiency in patients undergoing PD in a crosssectional study (21). Additionally, we found a significant association between the acyl carnitine/free carnitine ratio and the erythropoietin resistance index (ERI) in this population (21). The ERI is an indicator for the severity of erythropoietinresistant anemia $(22,23)$, and it is associated with the mortality rate in patients undergoing dialysis (23). Therefore, carnitine deficiency is considered to be an important pathological condition in patients undergoing hemodialysis and in patients undergoing PD. The utility of carnitine supplementation in the patients undergoing PD remains unclear because, to date, it has not been fully investigated. Therefore, in the present study, we retrospectively investigated the effects of carnitine supplementation in patients with carnitine deficiency who were undergoing PD.

\section{MATERIALS AND METHODS Study Design}

This was a single-center, retrospective, and observational study. We compared serum carnitine concentrations (free carnitine, acyl carnitine, and total carnitine) and other clinical variables before and after 4-6 months of oral carnitine supplementation.

\section{Study Population}

This study was conducted at Saitama Medical Center, Jichi Medical University between September 2016 and August 2021. We included patients undergoing PD who were administered carnitine for 4-6 months to treat carnitine deficiency. Inclusion criteria were as follows: (i) patients undergoing PD diagnosed with carnitine deficiency (based on criteria discussed below); (ii) patients supplemented with carnitine for 4-6 months; (iii) patients whose carnitine concentrations were measured before and after carnitine supplementation; and (iv) age $>18$ years. Exclusion criteria were as follows: (i) patients with acute kidney injury; (ii) patients who underwent renal transplantation; (iii) patients undergoing additional hemodialysis; and (iv) patients who refused to participate in the study. Patients who were diagnosed with carnitine deficiency and did not receive carnitine supplementation were designated as the control group. The control group was followed-up for 6 months, which included evaluation of clinical variables. All patients undergoing PD were treated according to the 2009 Japanese Society for Dialysis Therapy Guideline for PD and 2015 Japanese Society for Dialysis Therapy Guideline for Renal Anemia in Chronic Kidney Disease $(24,25)$. This study was approved by the Saitama Medical Center, Jichi Medical University Ethics Committee (DAI-RIN 15-34) and was conducted in accordance with the Declaration of Helsinki. Patients were notified of their option to opt out of the study.

\section{Data Collection}

We obtained patient data from medical records. These included age, sex, body mass index, systolic blood pressure, diastolic blood pressure, comorbidities (diabetes mellitus, hepatic diseases, cardiac diseases, malignant tumor and bone marrow disease), Administration renin-angiotensin inhibitor, Amount of PD fluid, Amount of water removal, Amount of urine, Energy intake, Protein intake, $\mathrm{PD}$ period, $\mathrm{PD}$ modalities, dialysis efficiency (weekly Kt/V urea, peritoneal Kt/V urea, and renal $\mathrm{Kt} / \mathrm{V}$ urea), 4-h dialysate/plasma creatinine, ejection fraction, cardio-thoracic ratio, blood tests, and dialysate tests. PD modalities were categorized as either continuous ambulatory peritoneal dialysis (CAPD) or automated peritoneal dialysis (APD). CAPD is a method whereby patients manually change the dialysate, whereas in APD, the dialysate is changed automatically by an automated cycler (26-29). Peritoneal weekly $\mathrm{Kt} / \mathrm{V}$ urea was used as indicator of efficacy of PD, and renal weekly $\mathrm{Kt} / \mathrm{V}$ was used as indicator of residual renal function (30). Their summation was defined as total weekly $\mathrm{Kt} / \mathrm{V}$ urea (30). 4-h dialysate/plasma creatinine is an indicator of permeability of peritoneal membranes (31). Ejection fraction was measured by echocardiography. The Cardio-thoracic ratio was measured by chest X-ray. Serum total carnitine and free carnitine concentrations were determined at a clinical chemistry laboratory (SRL, Tokyo, Japan). They were measured using the enzyme cycling method (6). Acyl carnitine concentrations were calculated as total carnitine minus free carnitine (7). Blood tests (except for carnitine and dialysate tests) were performed by the Department of Clinical Laboratory, Saitama Medical Center, Jichi Medical University. 
TABLE 1 | Features of the study population.

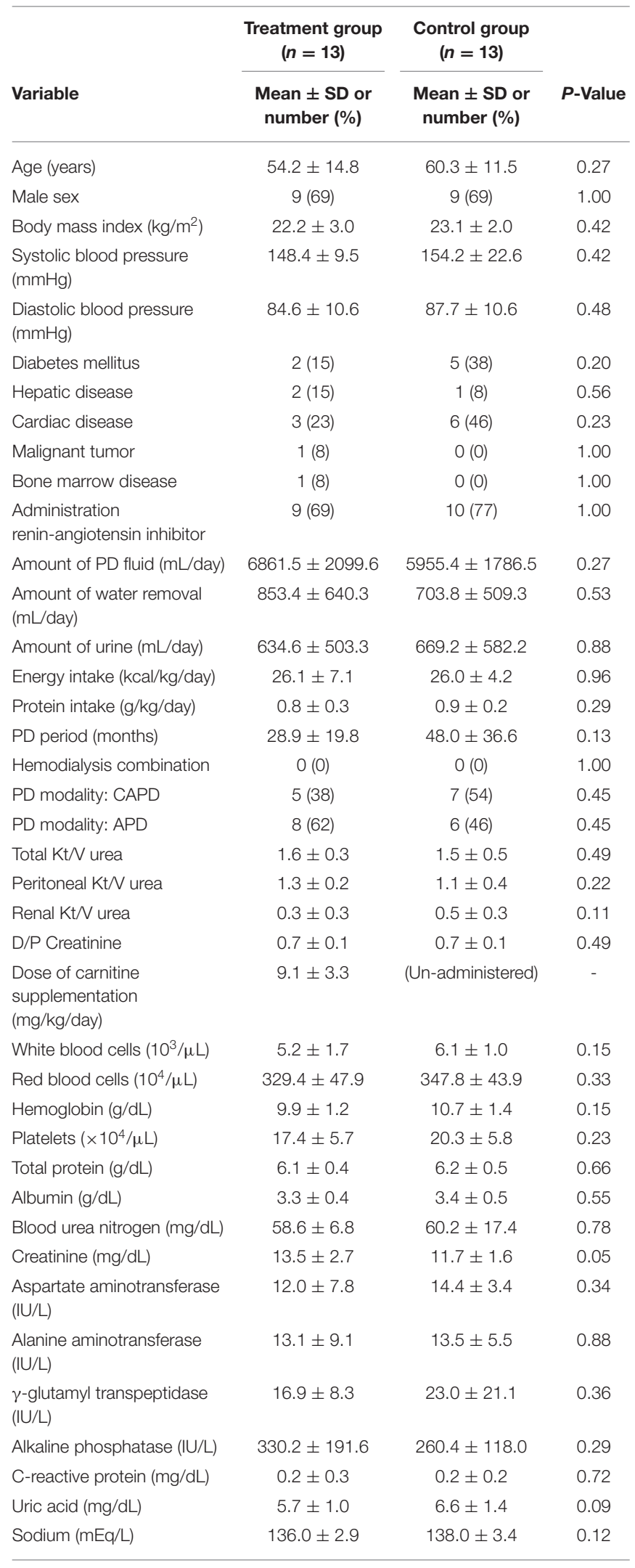

(Continued)
TABLE 1 | Continued

\begin{tabular}{|c|c|c|c|}
\hline & $\begin{array}{l}\text { Treatment group } \\
\qquad(n=13) \\
\end{array}$ & $\begin{array}{l}\text { Control group } \\
\qquad(n=13)\end{array}$ & \\
\hline Variable & $\begin{array}{c}\text { Mean } \pm \text { SD or } \\
\text { number (\%) }\end{array}$ & $\begin{array}{c}\text { Mean } \pm \text { SD or } \\
\text { number (\%) }\end{array}$ & $P$-Value \\
\hline Potassium (mEq/L) & $4.7 \pm 0.5$ & $4.4 \pm 0.8$ & 0.27 \\
\hline Chloride (mEq/L) & $97.4 \pm 4.9$ & $99.3 \pm 3.9$ & 0.30 \\
\hline Corrected calcium (mg/dL) & $9.4 \pm 0.6$ & $9.2 \pm 0.8$ & 0.39 \\
\hline Phosphorus (mg/dL) & $5.5 \pm 1.4$ & $5.7 \pm 1.3$ & 0.71 \\
\hline Magnesium (mg/dL) & $2.0 \pm 0.2$ & $2.2 \pm 0.4$ & 0.13 \\
\hline Zinc ( $\mu \mathrm{g} / \mathrm{dL})$ & $71.3 \pm 20.6$ & $59.6 \pm 7.94$ & 0.09 \\
\hline Iron ( $\mu \mathrm{g} / \mathrm{dL})$ & $123.0 \pm 40.2$ & $91.8 \pm 38.4$ & 0.07 \\
\hline Ferritin (mg/mL) & $202.8 \pm 113.1$ & $202.1 \pm 147.7$ & 0.99 \\
\hline Transferrin saturation (\%) & $47.1 \pm 11.4$ & $35.2 \pm 15.4$ & 0.06 \\
\hline Vitamin B12 (pg/mL) & $653.0 \pm 330.1$ & $513.5 \pm 183.5$ & 0.65 \\
\hline Folate $(\mathrm{ng} / \mathrm{mL})$ & $4.5 \pm 1.4$ & $3.2 \pm 0.6$ & 0.38 \\
\hline Blood sugar (mg/dL) & $111.0 \pm 18.4$ & $114.6 \pm 22.1$ & 0.67 \\
\hline $\mathrm{HbA} 1 \mathrm{c}(\%)$ & $5.2 \pm 0.3$ & $5.3 \pm 0.5$ & 0.45 \\
\hline Total carnitine ( $\mu \mathrm{mol} / \mathrm{L})$ & $48.5 \pm 10.2$ & $45.7 \pm 14.5$ & 0.60 \\
\hline Acyl carnitine ( $\mu \mathrm{mol} / \mathrm{L})$ & $17.4 \pm 2.8$ & $18.5 \pm 6.8$ & 0.60 \\
\hline Free carnitine ( $\mu \mathrm{mol} / \mathrm{L})$ & $31.1 \pm 8.3$ & $27.2 \pm 8.7$ & 0.28 \\
\hline $\begin{array}{l}\text { Acyl carnitine/free carnitine } \\
\text { ratio }\end{array}$ & $0.6 \pm 0.2$ & $0.7 \pm 0.2$ & 0.13 \\
\hline Total cholesterol (mg/dL) & $180.8 \pm 30.8$ & $177.8 \pm 46.6$ & 0.85 \\
\hline HDL cholesterol (mg/dL) & $52.8 \pm 13.5$ & $49.3 \pm 9.7$ & 0.48 \\
\hline LDL cholesterol (mg/dL) & $103.3 \pm 23.7$ & $100.4 \pm 42.3$ & 0.84 \\
\hline Triglycerides (mg/dL) & $113.2 \pm 39.2$ & $114.2 \pm 42.9$ & 0.95 \\
\hline Intact PTH (pg/dL) & $226.1 \pm 135.8$ & $229.2 \pm 120.8$ & 0.95 \\
\hline ERI [IU/Kg/(g/dL)/week] & $13.7 \pm 4.7$ & $6.9 \pm 2.6$ & $<0.01$ \\
\hline Ejection fraction (\%) & $60.1 \pm 8.4$ & $60.2 \pm 13.2$ & 0.98 \\
\hline Cardio-thoracic ratio (\%) & $48.3 \pm 5.2$ & $50.4 \pm 5.5$ & 0.35 \\
\hline
\end{tabular}

$S D$, standard deviation; $P D$, peritoneal dialysis; $C A P D$, continuous ambulatory peritoneal dialysis; APD, automated peritoneal dialysis; D/P Creatinine, 4-h dialysate/plasma creatinine ratio; HDA1c, hemoglobin A1c; HDL, high-density lipoprotein; $L D L$, low-density lipoprotein; PTH, parathormone; ERI, erythropoietin resistance index.

\section{Definition of Carnitine Deficiency}

Diagnosis of carnitine deficiency was based on Japanese guidelines (low free carnitine $(<36 \mu \mathrm{mol} / \mathrm{L})$ and/or high acyl carnitine/free carnitine ratio $(>0.4)$ ) (8). This guideline was published by the Japan Pediatric Society in 2018 (8).

\section{Carnitine Supplementation}

Japanese guidelines recommend carnitine supplementation at doses of $10-20 \mathrm{mg} /$ body weight $(\mathrm{kg})$ in patients undergoing PD diagnosed with carnitine deficiency (8). However, this dose was not supported by previous reports. Dosage was determined based on these guidelines and the tolerability of patients. After 4-6 months, serum carnitine concentrations (free carnitine, acyl carnitine, and total carnitine) were remeasured.

\section{Erythropoietin Resistance Index}

ERI was used as indicator of resistance of renal anemia to erythropoietin-stimulating agents $(22,23)$. ERI was defined 
as average weekly dose of recombinant human erythropoietin (IU)/body weight $(\mathrm{kg}) /$ hemoglobin $(\mathrm{g} / \mathrm{dL})(22,23)$. For dose conversion of recombinant human erythropoietin, the ratio of recombinant human erythropoietin: darbepoetin alfa or epoetin beta pegol was converted to 200:1 (32). Changes in ERI in individual patients were analyzed as the ERI change rate. The ERI change rate was calculated as follows: ERI (after carnitine supplementation) / ERI (baseline).

TABLE 2 | Effects of carnitine supplementation on clinical variables.

\begin{tabular}{|c|c|c|c|c|c|c|}
\hline Variable & \multicolumn{3}{|c|}{ Treatment group $(n=13)$} & \multicolumn{3}{|c|}{ Control group $(n=13)$} \\
\hline Diastolic blood pressure (mmHg) & $84.6 \pm 10.6$ & $86.7 \pm 9.4$ & 0.62 & $87.7 \pm 10.6$ & $80.4 \pm 14.6$ & 0.17 \\
\hline White blood cells $\left(10^{3} / \mu \mathrm{L}\right)$ & $5.2 \pm 1.7$ & $5.3 \pm 1.4$ & 0.89 & $6.1 \pm 1.0$ & $5.7 \pm 1.4$ & 0.48 \\
\hline Red blood cells $\left(10^{4} / \mu \mathrm{L}\right)$ & $329.4 \pm 47.9$ & $330.6 \pm 43.8$ & 0.95 & $347.8 \pm 43.9$ & $350.3 \pm 30.9$ & 0.88 \\
\hline Total protein (g/dL) & $6.1 \pm 0.4$ & $6.1 \pm 0.4$ & 0.90 & $6.2 \pm 0.5$ & $5.9 \pm 0.4$ & 0.10 \\
\hline Albumin (g/dL) & $3.3 \pm 0.4$ & $3.2 \pm 0.3$ & 0.49 & $3.4 \pm 0.5$ & $3.1 \pm 0.5$ & 0.10 \\
\hline Blood urea nitrogen (mg/dL) & $58.6 \pm 6.8$ & $60.3 \pm 17.2$ & 0.75 & $60.2 \pm 17.4$ & $62.6 \pm 14.1$ & 0.71 \\
\hline Creatinine (mg/dL) & $13.5 \pm 2.7$ & $13.4 \pm 3.7$ & 0.72 & $11.7 \pm 1.6$ & $11.8 \pm 1.3$ & 0.85 \\
\hline Aspartate aminotransferase (IU/L) & $12.0 \pm 7.8$ & $12.5 \pm 4.7$ & 0.86 & $14.4 \pm 3.4$ & $15.2 \pm 5.4$ & 0.68 \\
\hline C-reactive protein (mg/dL) & $0.2 \pm 0.3$ & $0.3 \pm 0.3$ & 0.52 & $0.2 \pm 0.2$ & $0.2 \pm 0.3$ & 0.92 \\
\hline Uric acid (mg/dL) & $5.7 \pm 1.0$ & $5.6 \pm 0.8$ & 0.80 & $6.6 \pm 1.4$ & $6.4 \pm 1.1$ & 0.75 \\
\hline Sodium (mEq/L) & $136.0 \pm 2.9$ & $137.0 \pm 3.2$ & 0.22 & $138.0 \pm 3.4$ & $137.0 \pm 2.7$ & 0.65 \\
\hline Potassium (mEq/L) & $4.7 \pm 0.5$ & $4.7 \pm 0.5$ & 0.81 & $4.4 \pm 0.8$ & $4.5 \pm 0.7$ & 0.90 \\
\hline Chloride (mEq/L) & $97.4 \pm 4.9$ & $98.9 \pm 4.2$ & 0.43 & $99.3 \pm 3.9$ & $99.2 \pm 3.0$ & 0.91 \\
\hline Corrected calcium (mg/dL) & $9.4 \pm 0.6$ & $9.0 \pm 0.6$ & 0.10 & $9.2 \pm 0.8$ & $9.4 \pm 0.5$ & 0.38 \\
\hline Phosphorus (mg/dL) & $5.5 \pm 1.4$ & $5.8 \pm 1.2$ & 0.52 & $5.7 \pm 1.3$ & $5.6 \pm 1.2$ & 0.86 \\
\hline Magnesium (mg/dL) & $2.0 \pm 0.2$ & $2.1 \pm 0.3$ & 0.52 & $2.2 \pm 0.4$ & $2.1 \pm 0.3$ & 0.30 \\
\hline Zinc ( $\mu \mathrm{g} / \mathrm{dL})$ & $71.3 \pm 20.6$ & $73.0 \pm 20.6$ & 0.87 & $59.6 \pm 7.94$ & $61.2 \pm 11.8$ & 0.72 \\
\hline Iron ( $\mu \mathrm{g} / \mathrm{dL})$ & $123.0 \pm 40.2$ & $93.2 \pm 29.2$ & 0.05 & $91.8 \pm 38.4$ & $86.7 \pm 34.8$ & 0.73 \\
\hline Acyl carnitine ( $\mu \mathrm{mol} / \mathrm{L})$ & $17.4 \pm 2.8$ & $46.9 \pm 13.8$ & $<0.01$ & $18.5 \pm 6.8$ & (unmeasured) & - \\
\hline Free carnitine ( $\mu \mathrm{mol} / \mathrm{L})$ & $31.1 \pm 8.3$ & $83.1 \pm 24.6$ & $<0.01$ & $27.2 \pm 8.7$ & (unmeasured) & - \\
\hline Acyl carnitine/free carnitine ratio & $0.6 \pm 0.1$ & $0.6 \pm 0.1$ & 0.75 & $0.7 \pm 0.2$ & (unmeasured) & - \\
\hline Total cholesterol (mg/dL) & $180.8 \pm 30.8$ & $188.5 \pm 23.9$ & 0.50 & $177.8 \pm 46.6$ & $152.5 \pm 38.0$ & 0.17 \\
\hline HDL cholesterol (mg/dL) & $52.8 \pm 13.5$ & $53.5 \pm 11.4$ & 0.88 & $49.3 \pm 9.7$ & $45.0 \pm 10.1$ & 0.31 \\
\hline LDL cholesterol (mg/dL) & $103.3 \pm 23.7$ & $111.8 \pm 18.4$ & 0.34 & $100.4 \pm 42.3$ & $80.9 \pm 34.7$ & 0.24 \\
\hline Triglycerides (mg/dL) & $113.2 \pm 39.2$ & $109.9 \pm 46.8$ & 0.85 & $114.2 \pm 42.9$ & $114.5 \pm 49.5$ & 0.99 \\
\hline Intact PTH (pg/dL) & $226.1 \pm 135.8$ & $288.2 \pm 175.3$ & 0.34 & $229.2 \pm 120.8$ & $194.4 \pm 90.4$ & 0.44 \\
\hline ERI [IU/Kg/(g/dL)/week] & $13.7 \pm 4.7$ & $11.6 \pm 3.4$ & 0.28 & $6.9 \pm 2.6$ & $8.1 \pm 3.0$ & 0.28 \\
\hline Change rate of ERI & $1.00 \pm 0.00$ & $0.87 \pm 0.11$ & $<0.01$ & $1.00 \pm 0.00$ & $1.19 \pm 3.0$ & $<0.01$ \\
\hline Ejection fraction (\%) & $60.1 \pm 8.4$ & $60.2 \pm 13.2$ & 0.98 & $60.2 \pm 13.2$ & $67.0 \pm 7.0$ & 0.69 \\
\hline Cardio-thoracic ratio (\%) & $48.3 \pm 5.2$ & $48.7 \pm 5.9$ & 0.86 & $50.4 \pm 5.5$ & $51.7 \pm 4.1$ & 0.51 \\
\hline
\end{tabular}

HbA1c, hemoglobin A1c; HDL, high-density lipoprotein; LDL, low-density lipoprotein; PTH, parathormone; ERI, erythropoietin resistance index. 


\section{Statistical Analysis}

Quantitative variables are presented as mean \pm standard deviation. Categorical variables are presented as frequency and percentage. Continuous variables were compared using the paired $t$-test. Frequency was compared using Fisher's exact test. Statistical analyses were performed using JMP (SAS Institute Inc., Cary, NC, USA). $P<0.05$ was considered statistically significant.

\section{RESULTS}

\section{Clinical Features of the Study Population}

There were 13 patients in the treatment group and 13 patients in the control group who met the study entry criteria. Features of the study population are shown in Table 1. In the treatment group, the mean age was $54.2 \pm 14.8$ years, and nine of 13 patients were men (69\%). The mean body mass index was 22.2 $\pm 3.0 \mathrm{~kg} / \mathrm{m}^{2}$. The mean PD period was $28.9 \pm 19.8$ months. Five (38\%) patients underwent CAPD, while eight (62\%) patients underwent APD. The mean total Kt/V urea, peritoneal Kt/V urea, and renal Kt/V urea were $1.6 \pm 0.3,1.3 \pm 0.2$, and $0.3 \pm 0.3$, respectively. The mean carnitine supplementation dose was 9.1 $\pm 3.3 \mathrm{mg} / \mathrm{kg} /$ day. In the control group, the mean age was $60.3 \pm$ 11.5 years, and nine of 13 patients were men (69\%). The mean body mass index was $23.1 \pm 2.0 \mathrm{~kg} / \mathrm{m}^{2}$. The mean PD period was $48.0 \pm 36.6$ months. A significant difference in the mean ERI between the two groups was observed $(13.7 \pm 4.7$ vs. $6.9 \pm 2.6$ $[\mathrm{IU} / \mathrm{kg} /(\mathrm{g} / \mathrm{dL}) /$ week], $P<0.01)$.

\section{Effects of Carnitine Supplementation on Carnitine Concentrations}

Changes in carnitine concentrations in response to carnitine supplementation are shown in Table 2. Carnitine supplementation increased serum total carnitine $(48.5 \pm 10.2$ vs. $130.1 \pm 37.2 \mu \mathrm{mol} / \mathrm{L}, P<0.01)$, free carnitine $(31.1 \pm 8.3 \mathrm{vs}$. $83.1 \pm 24.6 \mu \mathrm{mol} / \mathrm{L}, P<0.01)$, and acyl carnitine $(17.4 \pm 2.8$ vs. $46.9 \pm 13.8, P<0.01)$. The acyl carnitine/free carnitine ratio was not affected by carnitine supplementation $(0.6 \pm 0.1$ vs. $0.6 \pm$ $0.1, P=0.75)$.

\section{Effects of Carnitine Supplementation on ERI}

The effects of carnitine supplementation on clinical variables, including ERI, are shown in Table 2 and Figure 1. In the treatment group, two patients who developed severe infections and one who developed severe anemia of unknown cause were excluded from the ERI analysis. Although oral carnitine supplementation had a tendency to decrease the mean ERI value, there was no significant difference between the two groups [13.7 \pm 4.7 vs. $11.6 \pm 3.4 \mathrm{IU} / \mathrm{kg} /(\mathrm{g} / \mathrm{dL}) /$ week, $P=0.28]$. However, the change rate of ERI was significantly decreased by carnitine supplementation $(1.00 \pm 0.00$ vs. $0.87 \pm 0.11, P<0.01)$. In the control group, the mean ERI value did not change ( $6.9 \pm 2.6$ vs. $8.1 \pm 3.0 \mathrm{IU} / \mathrm{kg} /(\mathrm{g} / \mathrm{dL}) /$ week, $P=0.28)$ and the ERI change rate was significantly increased $(1.00 \pm 0.00$ vs. $1.19 \pm 3.0, P<0.01)$ after 6 months of follow-up. No other clinical parameters were affected by carnitine supplementation in this study.

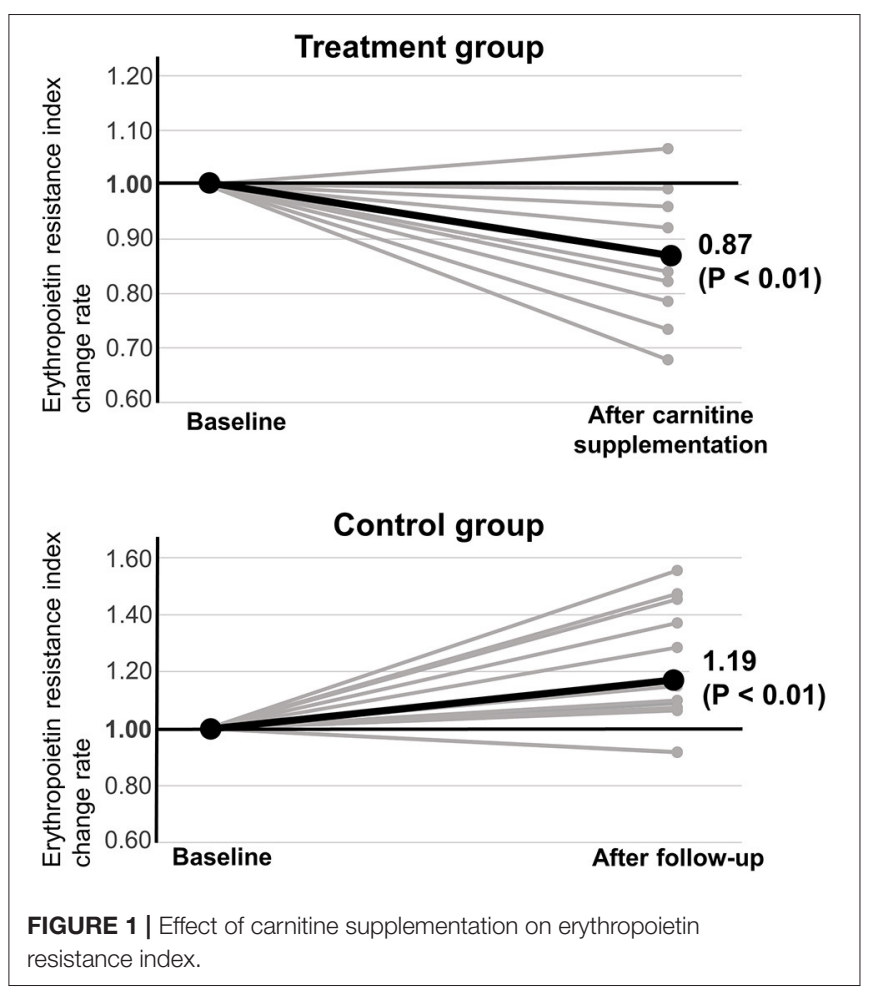

\section{DISCUSSION}

In this study, 4-6 months of oral carnitine supplementation (mean dose: $9.1 \pm 3.3 \mathrm{mg} / \mathrm{kg} /$ day) in patients undergoing $\mathrm{PD}$ increased total carnitine, free carnitine, and acylcarnitine levels, and did not affect the acyl carnitine/free carnitine ratio. Although carnitine supplementation did not decrease the mean ERI value, the ERI change rate was significantly decreased. In the control group, the mean ERI value was not changed after 6 months of follow-up and the ERI change rate was significantly increased. These results suggest that erythropoietin resistance in patients who are undergoing PD may be improved by oral carnitine supplementation. The difference in the baseline ERI between the two groups $(13.7 \pm 4.7$ vs. $6.9 \pm 2.6[\mathrm{IU} / \mathrm{kg} /(\mathrm{g} / \mathrm{dL}) /$ week $], P<$ $0.01)$ may be because we preferentially administered carnitine to patients with severe erythropoietin resistance in accordance with the guidelines (14). Although this short-term observational study had a small sample size, the results are important because few similar studies have been conducted $(19,20)$. In Japan, carnitine measurement was covered by public medical insurance starting in February 2018, and we expect that the details on carnitine deficiency in patients who are undergoing PD will be gradually clarified in the future.

In patients undergoing $\mathrm{PD}$, carnitine deficiency can be explained by several factors. First, patients with kidney disease, including those undergoing PD, must follow dietary restrictions. Therefore, oral intake of carnitine is reduced $(11,12)$. Second, because carnitine is biosynthesized in the kidney, it tends to be deficient in patients with impaired renal function $(11,12)$. Third, loss of carnitine in PD fluid is also possible (33). Although 
a previous study showed that APD contributed more to free carnitine loss than CAPD (34), our previous studies did not show the same results (21). Additionally, the hemodialysis combination (daily PD + hemodialysis once a week) did not affect the carnitine level in our previous study (21).

At present, there are few reports on carnitine supplementation in patients undergoing $\operatorname{PD}(19,20)$. The National Kidney Foundation recommends 9-12 months of carnitine supplementation for dialysis patients. However, this is intended for patients undergoing hemodialysis, not those undergoing PD (14). Japanese guidelines propose oral carnitine supplementation at $10-20 \mathrm{mg} / \mathrm{kg}$ in patients undergoing $\mathrm{PD}$, although there are no previous reports that support these guidelines. Therefore, the optimal treatment period, supplementation dose, and monitoring frequency for carnitine deficiency in patients who are undergoing PD have not been established. To avoid unexpected adverse effects, we performed a relatively short-term study (4-6 months) using a relatively small dose $(9.1 \pm 3.3$ $\mathrm{mg} / \mathrm{kg} /$ day) of carnitine.

We previously reported the importance of the acyl carnitine/free carnitine ratio for diagnosing carnitine deficiency in patients undergoing PD (21). In the current study, ERI decreased following carnitine supplementation with increasing levels of both free carnitine (from $17.4 \pm 3.0$ to $46.9 \pm 14.5$ $\mu \mathrm{mol} / \mathrm{L}$ ) and acyl carnitine (from $31.1 \pm 8.6$ to $83.1 \pm 25.8$ $\mu \mathrm{mol} / \mathrm{L})$. The acyl carnitine/free carnitine ratio was not changed by carnitine supplementation. According to these results, increased free carnitine level may be more effectives than corrected balance of acyl carnitine/free carnitine ratio for improving ERI in patients undergoing PD. Future studies with larger sample sizes and longer observational periods are required to further clarify the effects and proper monitoring of carnitine supplementation in patients undergoing PD with carnitine deficiency.

Carnitine is considered to be associated with red blood cell deformability $(22,35,36)$. Therefore, carnitine deficiency is considered to be one of the factors that caused the increased ERI (21). To our knowledge, there are only two reports on the effects of carnitine supplementation on erythropoietin-resistant anemia in patients undergoing PD $(19,20)$. Sotirakopoulos et al. reported that anemia improved in 12 patients undergoing PD who received carnitine supplementation (19). In contrast, Lilien et al. reported that carnitine supplementation did not improve anemia in four pediatric patients undergoing PD (20). The differences between these reports and our report may be explained by oral medication adherence. Poor oral medication adherence is often a serious problem in clinical settings. At our institution, we thoroughly checked the oral medication adherence and confirmed that the patients did not miss a dose. Additionally,

\section{REFERENCES}

1. Adeva-Andany MM, Calvo-Castro I, Fernández-Fernández C, DonapetryGarcía C, Pedre-Piñeiro AM. Significance of l-carnitine for human health. IUBMB Life. (2017) 69:578-94. doi: 10.1002/iub.1646 the effects of carnitine supplementation on erythropoietinresistant anemia may be associated with differences in the carnitine supplementation dose, supplementation period, and patient background.

This study had important limitations. First, this was an observational study with a small sample size, and additional large-scale studies are needed. Second, it was conducted at a single facility. Third, carnitine supplementation was only administered orally, and carnitine-containing PD fluid was not considered. Fourth, the results may have been affected by differences in carnitine supplementation dose and period. Fifth, this finding cannot be applied to patients without carnitine deficiency. Large-scale interventional studies are required to clarify the effectiveness of carnitine supplementation in patients who are undergoing PD with carnitine deficiency.

\section{CONCLUSIONS}

Carnitine supplementation may improve erythropoietin resistance in patients undergoing $\mathrm{PD}$.

\section{DATA AVAILABILITY STATEMENT}

The raw data supporting the conclusions of this article will be made available by the authors, without undue reservation.

\section{ETHICS STATEMENT}

The studies involving human participants were reviewed and approved by Saitama Medical Center, Jichi Medical University Ethics Committee (DAI-RIN 15-34). Written informed consent for participation was not required for this study in accordance with the National Legislation and the Institutional requirements.

\section{AUTHOR CONTRIBUTIONS}

SK: conceptualization, methodology, software, validation, formal analysis, investigation, resources, visualization, and writingoriginal draft preparation. SK, KY, TK, HM, KH, SO, and YM: data curation. SK and YM: writing-review and editing. YM: supervision and project administration. All authors have read and agreed to the published version of the manuscript.

\section{ACKNOWLEDGMENTS}

We thank the medical staff of the dialysis department of Saitama Medical Center, Jichi Medical University. We thank Richard Robins, from Edanz Group (https://en-author-services.edanz. com/ac) for editing a draft of this manuscript. 
4. Naseri M, Moghadam Shahri HM, Horri M, Esmaeeli M, Ghaneh Sherbaf F, Jahanshahi S, et al. Absolute and relative carnitine deficiency in patients on hemodialysis and peritoneal dialysis. Iran J Kidney Dis. (2016) 10:36-43.

5. Zhang YM, Zhuo L, Hu J, Cui G, Zhang L, Zhang XL, et al. Clinical significance of different carnitine levels for improving the prognosis of patients undergoing hemodialysis. Ren Fail. (2016) 38:1654-8. doi: 10.1080/0886022X.2016.1229967

6. Takahashi M, Ueda S, Misaki H, Sugiyama N, Matsumoto K, Matsuo N, et al. Carnitine determination by an enzymatic cycling method with carnitine dehydrogenase. Clin Chem. (1994) 40:817-21. doi: 10.1093/clinchem/40.5.817

7. Rebouche CJ, Engel AG. Carnitine metabolism and deficiency syndromes. Mayo Clin Proc. (1983) 58:533-40.

8. Japan Pediatric Society. Available online at: http://www.jpeds.or.jp/uploads/ files/20181207_shishin.pdf (accessed September 1, 2020).

9. Yang SK, Xiao L, Song PA, Xu X, Liu FY, Sun L. Effect of L-carnitine therapy on patients in maintenance hemodialysis: a systematic review and meta-analysis. J Nephrol. (2014) 27:317-29. doi: 10.1007/s40620-013-0002-7

10. Hatanaka Y, Higuchi T, Akiya Y, Horikami T, Tei R, Furukawa T, et al. Prevalence of carnitine deficiency and decreased carnitine levels in patients on hemodialysis. Blood Purif. (2019) 47(Suppl 2):38-44. doi: 10.1159/000496720

11. Evans AM, Faull RJ, Nation RL, Prasad S, Elias T, Reuter SE, et al. Impact of hemodialysis on endogenous plasma and muscle carnitine levels in patients with end-stage renal disease. Kidney Int. (2004) 66:1527-34. doi: 10.1111/j.1523-1755.2004.00916.x

12. Evans A. Dialysis-related carnitine disorder and levocarnitine pharmacology. Am J Kidney Dis. (2003) 41(4 Suppl 4):S13-26. doi: 10.1016/ S0272-6386(03)00113-6

13. Sirolli V, Rossi C, Di Castelnuovo A, Felaco P, Amoroso L, Zucchelli M, et al. Toward personalized hemodialysis by low molecular weight aminocontaining compounds: future perspective of patient metabolic fingerprint. Blood Transfus. (2012) 10(Suppl 2):s78-88. doi: 10.2450/2012.012S

14. Eknoyan G, Latos DL, Lindberg J. Practice recommendations for the use of L-carnitine in dialysis-related carnitine disorder. National kidney foundation carnitine consensus conference. Am J Kidney Dis. (2003) 41:86876. doi: 10.1016/S0272-6386(03)00110-0

15. Xu Y, Jiang W, Chen G, Zhu W, Ding W, Ge Z, et al. L-carnitine treatment of insulin resistance: a systematic review and meta-analysis. Adv Clin Exp Med. (2017) 26:333-8. doi: 10.17219/acem/61609

16. Askarpour M, Djafarian K, Ghaedi E, Sadeghi O, Sheikhi A, Shab-Bidar S. Effect of L-carnitine supplementation on liver enzymes: a systematic review and meta-analysis of randomized controlled trials. Arch Med Res. (2020) 51:82-94. doi: 10.1016/j.arcmed.2019.12.005

17. Hanai T, Shiraki M, Imai K, Suetugu A, Takai K, Shimizu M. Usefulness of carnitine supplementation for the complications of liver cirrhosis. Nutrients. (2020) 12:1915. doi: 10.3390/nu12071915

18. Savic D, Hodson L, Neubauer S, Pavlides M. The importance of the fatty acid transporter L-carnitine in non-alcoholic fatty liver disease (NAFLD). Nutrients. (2020) 12:2178. doi: 10.3390/nu12082178

19. Sotirakopoulos N, Athanasiou G, Tsitsios T, Mavromatidis K. The influence of L-carnitine supplementation on hematocrit and hemoglobin levels in patients with end stage renal failure on CAPD. Ren Fail. (2002) 24:505-10. doi: 10.1081/JDI-120006777

20. Lilien MR, Duran M, Quak JM, Frankhuisen JJ, Schröder CH. Oral L-carnitine does not decrease erythropoietin requirement in pediatric dialysis. Pediatr Nephrol. (2000) 15:17-20. doi: 10.1007/s004670000423

21. Kaneko S, Hirai K, Morino J, Minato S, Yanai K, Mutsuyoshi Y, et al. Association between carnitine deficiency and the erythropoietin resistance index in patients undergoing peritoneal dialysis: a crosssectional observational study. Ren Fail. (2020) 42:146-53. doi: 10.1080/ 0886022X.2020.1719847

22. Kamei D, Tsuchiya K, Nitta K, Mineshima M, Akiba T. Association between resistance to erythropoiesis-stimulating agents and carnitine profile in patients on maintenance haemodialysis. Nephrology. (2018) 23:737-43. doi: $10.1111 /$ nep.13079

23. Hayashi T, Joki N, Tanaka Y, Iwasaki M, Kubo S, Matsukane A, et al. Resistance to erythropoiesis-stimulating agents in pre-dialysis and post-dialysis mortality in japanese incident hemodialysis patients. Blood Purif. (2019) 47(Suppl 2):31-7. doi: 10.1159/000496634

24. Working Group Committee for Preparation of Guidelines for Peritoneal Dialysis, Japanese Society for Dialysis Therapy. 2009 Japanese society for dialysis therapy guidelines for peritoneal dialysis. Ther Apher Dial. (2010) 14:489-504. doi: 10.1111/j.1744-9987.2010.00901.x

25. Yamamoto H, Nishi S, Tomo T, Masakane I, Saito K, Nangaku M, et al. 2015 Japanese society for dialysis therapy: guidelines for renal anemia in chronic kidney disease. Ren Replace Ther. (2017) 3:36. doi: 10.1186/s41100-017-0114-y

26. van Hoeck KJM, Rusthoven E, Vermeylen L, Vandesompel A, Marescau $B$, Lilien $M$, et al. Nutritional effects of increasing dialysis dose by adding an icodextrin daytime dwell to nocturnal intermittent peritoneal dialysis (NIPD) in children. Nephrol Dial Transplant. (2003) 18:1383-7. doi: $10.1093 / \mathrm{ndt} / \mathrm{gfg} 120$

27. Badve SV, Zimmerman DL, Knoll GA, Burns KD, McCormick BB. Peritoneal phosphate clearance is influenced by peritoneal dialysis modality, independent of peritoneal transport characteristics. Clin J Am Soc Nephrol. (2008) 3:1711-7. doi: 10.2215/CJN.00190108

28. Diaz-Buxo JA, Walker PJ, Chandler JT, Burgess WP, Farmer CD. Experience with intermittent peritoneal dialysis and continuous cyclic peritoneal dialysis. Am J Kidney Dis. (1984) 4:242-8. doi: 10.1016/S0272-6386(84)80099-2

29. Venkataraman V, Nolph KD. Utilization of PD modalities: evolution. Semin Dial. (2002) 15:380-4. doi: 10.1046/j.1525-139X.2002.00095.x

30. Lo W-K, Bargman JM, Burkart J, Krediet RT, Pollock C, Kawanishi $\mathrm{H}$, et al. Guideline on targets for solute and fluid removal in adult patients on chronic peritoneal dialysis. Perit Dial Int. (2006) 26:520-2. doi: 10.1177/089686080602600502

31. Teitelbaum I, Burkart J. Peritoneal dialysis. Am J Kidney Dis. (2003) 42:108296. doi: 10.1016/j.ajkd.2003.08.036

32. Aljama P, Bommer J, Canaud B, Carrera F, Eckardt KU, Hörl WH, et al. Practical guidelines for the use of NESP in treating renal anaemia. Nephrol Dial Transplant. (2001) 16(Suppl 3):22-8. doi: 10.1093/ndt/16.suppl_3.22

33. Grzegorzewska AE, Mariak I, Dobrowolska-Zachwieja A. Continuous ambulatory peritoneal dialysis (CAPD) adequacy influences serum free carnitine level. Int Urol Nephrol. (1999) 31:533-40. doi: 10.1023/A:1007127614765

34. Di Liberato L, Arduini A, Rossi C, Di Castelnuovo A, Posari C, Sacchetta $\mathrm{P}$, et al. L-carnitine status in end-stage renal disease patients on automated peritoneal dialysis. J Nephrol. (2014) 27:699-706. doi: 10.1007/s40620-014-0076-x

35. Bonomini M, Zammit V, Pusey CD, De Vecchi A, Arduini A. Pharmacological use of L-carnitine in uremic anemia: has its full potential been exploited? Pharmacol Res. (2011) 63:157-64. doi: 10.1016/j.phrs.2010. 11.006

36. Vlassopoulos DA, Hadjiyannakos DK, Anogiatis AG, Evageliou AE, Santikou $\mathrm{AV}$, Noussias CV, et al. Carnitine action on red blood cell osmotic resistance in hemodialysis patients. J Nephrol. (2002) 15:68-73.

Conflict of Interest: The authors declare that the research was conducted in the absence of any commercial or financial relationships that could be construed as a potential conflict of interest.

Publisher's Note: All claims expressed in this article are solely those of the authors and do not necessarily represent those of their affiliated organizations, or those of the publisher, the editors and the reviewers. Any product that may be evaluated in this article, or claim that may be made by its manufacturer, is not guaranteed or endorsed by the publisher.

Copyright (c) 2021 Kaneko, Yanai, Kitano, Miyazawa, Hirai, Ookawara and Morishita. This is an open-access article distributed under the terms of the Creative Commons Attribution License (CC BY). The use, distribution or reproduction in other forums is permitted, provided the original author(s) and the copyright owner(s) are credited and that the original publication in this journal is cited, in accordance with accepted academic practice. No use, distribution or reproduction is permitted which does not comply with these terms. 